\title{
Síndrome de artrogriposis, disfunción tubular renal y colestasis: causa de colestasis neonatal. A propósito de un caso Arthrogryposis-renal tubular dysfunction-cholestasis syndrome: a cause of neonatal cholestasis. Case report
}

\author{
Dr. Ozkan Ilhan ${ }^{a}$, Prof. Dra. Esra A. Ozer ${ }^{b}$, Dra. Senem A. Ozdemirc, Dra. Sinem Akbay ${ }^{d}$, \\ Dra. Seyma Memure, Dr. Berat Kanare y Prof. Dr. Mustafa M. Tatli ${ }^{d}$
}

\section{RESUMEN}

El síndrome de artrogriposis, disfunción tubular renal y colestasis es un trastorno fatal infrecuente que compromete múltiples aparatos y sistemas de órganos. Es un trastorno autosómico recesivo hereditario, causado por defectos en los genes VPS33B y VIPAR. Los tres signos primordiales de este síndrome son la artrogriposis, la disfunción tubular renal y la colestasis. Otros compromisos orgánicos a veces asociados con este síndrome son ictiosis, malformación del sistema nervioso central, anomalías trombocíticas, defectos cardíacos congénitos y grave retraso del crecimiento. Las manifestaciones clínicas, la biopsia de unórgano y los análisis de mutaciones pueden ayudar con el diagnóstico, pero no existe un tratamiento curativo; solamente puede instaurarse un tratamiento sintomático. Varios síntomas de esta afección usualmente se manifiestan en el período neonatal: artrogriposis, colestasis neonatal, lesiones cutáneas, entre otros. En general, la supervivencia se prolonga hasta el primer año de vida. Presentamos el caso de una recién nacida con una rápida evolución y desenlace fatal.

Palabras clave: artrogriposis, colestasis, disfunción tubular renal proximal, sindrome de artrogriposis, disfuncion renal y colestasis, neonato.

http:/ /dx.doi.org/10.5546/aap.2016.e9

a. Hospital Universitario y de Investigación de Tepecik, Departamento de Neonatología, Esmirna.

b. Muğla Sıtkı Koçman Üniversitesi, Facultad de Medicina, Departamento de Neonatología, Muğla.

c. Hospital Pediátrico Dr. Behcet Uz, Departamento de Neonatología, Esmirna.

d. İzmir Kâtip Çelebi Üniversitesi, Facultad de Medicina, Departamento de Neonatología, Esmirna.

e. Hospital Universitario y de Investigación de Tepecik, Departamento de Neonatología, Esmirna. Turquía.

Correspondencia:

Dr. Ozkan Ilhan: ozkanilhan-83@hotmail.com

Financiamiento: Ninguno.

Conflicto de intereses: Ninguno que declarar.

Recibido: 12-6-2015

Aceptado: 3-8-2015

\section{INTRODUCCIÓN}

El síndrome de artrogriposis, disfunción renal y colestasis (ARC) es un trastorno multisistémico autosómico recesivo que podría estar asociado con mutaciones en la estirpe germinal del gen VPS33B. ${ }^{1}$ El pronóstico de este síndrome es malo y la mayoría de los pacientes fallecen hacia los siete meses de edad debido a infecciones recurrentes, deshidratación grave, acidosis metabólica o hemorragias internas. ${ }^{2,3}$ Presentamos este caso debido a su rápido desenlace fatal.

\section{DESCRIPCIÓN DEL CASO}

Se hospitalizó a una recién nacida de un día de vida en la Unidad de Cuidados Intensivos Neonatales. Presentaba hipotonía, dificultad respiratoria, distensión abdominal y características dismórficas. Había nacido a las 38 semanas de gestación por cesárea debido a hidrocefalia y anomalías en las extremidades. Su peso al nacer fue $2000 \mathrm{~g}$. Sus padres eran turcos y primos hermanos. Al nacer, el estado general era malo y los puntajes de Apgar fueron bajos. Tenía una hermana sana, de cuatro años de edad. Un hermano nacido a las 28 semanas de gestación con características dismórficas había fallecido debido a dificultad respiratoria.

Al momento de la hospitalización, pesaba 2000 g, medía $38 \mathrm{~cm}$ de longitud y tenía un perímetro cefálico de $30 \mathrm{~cm}$ (todas las medidas por debajo del percentilo 3). Sus características dismórficas incluían puente nasal plano, paladar arqueado alto, nariz aguileña, piel laxa, micrognacia, orejas de implantación baja y microcefalia. Además, tenía hipotonía generalizada, dificultad respiratoria, hepatomegalia, distensión abdominal, abdomen en forma de campana y contracturas múltiples, tales como desviación radial de la muñeca, contractura en flexión de las articulaciones de la rodilla y pie cavo valgo. Se detectó fractura del fémur derecho mediante una radiografía. En la ecografía, se observó luxación de ambas 
articulaciones coxofemorales. Inicialmente, se diagnosticó artrogriposis múltiple congénita sobre la base de estas anomalías óseas.

Al momento de la hospitalización, la paciente tenía los siguientes valores: hemoglobina: 18,6 g/dl; leucocitos: $19500 / \mathrm{mm}^{3}$; trombocitos: $77000 / \mathrm{mm}^{3}$ (el frotis de sangre periférica mostró trombocitos pálidos y de gran tamaño); bilirrubina total en suero: $4,3 \mathrm{mg} / \mathrm{dl}$; bilirrubina conjugada: $0,7 \mathrm{mg} / \mathrm{dl}$. En el curso de 4 días, la niña desarrolló colestasis, deshidratación debido a poliuria, aumento de fosfatasa alcalina (FA) $(960 \mathrm{U} / \mathrm{L})$ y valor normal de $\gamma$-glutamiltransferasa $(\gamma-\mathrm{GT})(72 \mathrm{U} / \mathrm{L})$. A los cinco días de vida, los análisis de laboratorio mostraron bilirrubina total en suero: $13,5 \mathrm{mg} / \mathrm{dl}$; bilirrubina conjugada: $4,3 \mathrm{mg} / \mathrm{dl}$; aspartato aminotransferasa (AST): $555 \mathrm{U} / \mathrm{L}$; y fósforo: $2,7 \mathrm{mg} / \mathrm{dl}$. Los valores de proteínas y albúmina eran normales. Se observó una prolongación en las pruebas de coagulación. Los anticuerpos antivirales fueron negativos. Las pruebas de la función tiroidea fueron normales. Los niveles plasmáticos de alfa1-antitripsina y alfa-fetoproteína, el análisis de aminoácidos en sangre y orina y la espectrometría de masas en tándem estaban todos dentro de

FIgURA 1. Características dismórficas faciales: puente nasal plano, nariz aguileña, micrognacia, orejas de implantación baja y microcefalia

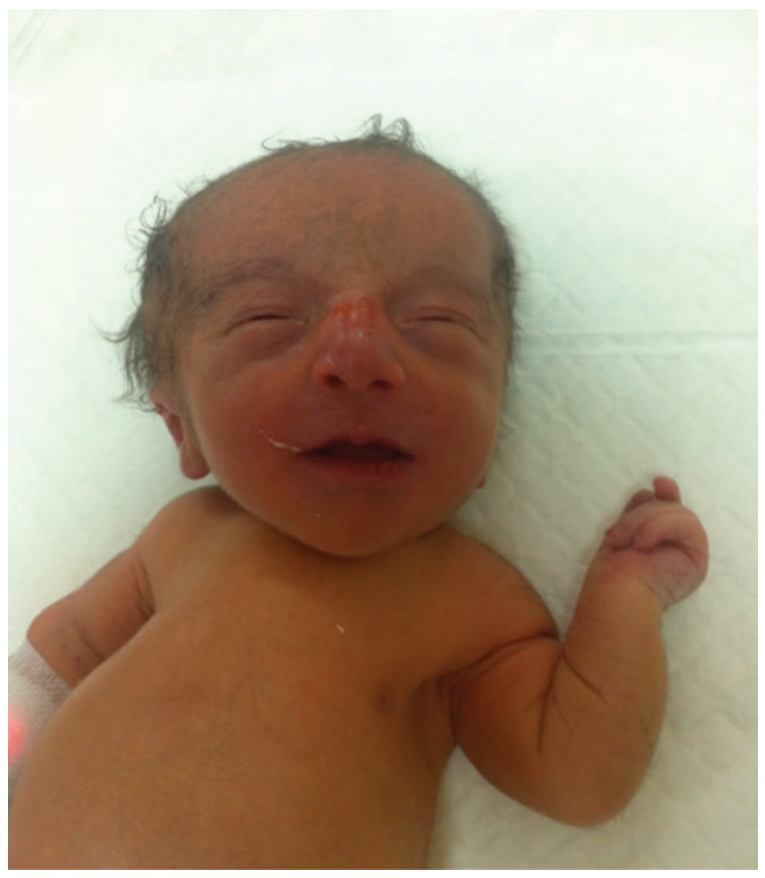

los límites normales. En las pruebas renales de la función tubular, se observó el incremento de la excreción fraccionada de sodio (EFNa: $4,89 \%$ ) y de la excreción fraccionada de potasio (EFK: 66\%), una baja reabsorción tubular de fósforo (RTF: $40 \%)$ y proteinuria $(167 \mathrm{mg} / \mathrm{dl})$. La gravedad específica de la orina era baja $(1,006)$. La gasometría arterial era normal. Sobre la base de estos signos clínicos (poliuria) y de laboratorio, se diagnosticó tubulopatía renal. Dado que la paciente producía orina diluida y tenía poliuria, se pensó que tenía diabetes insípida nefrógena. En una ecografía abdominal, se observó un leve aumento bilateral de la ecogenicidad renal. La colangiopancreatografía por resonancia magnética también era normal. En la tomografía computada cerebral, se observó dilatación de los ventrículos laterales y del tercer ventrículo y agenesia del cuerpo calloso. En la ecocardiografía, se halló una comunicación interauricular de tipo ostium secundum de $2 \mathrm{~mm}$. Dado que la biopsia

FIgURA 2. Fenotipo del sindrome de artrogriposis, disfunción renal y colestasis: distensión abdominal, abdomen en forma de campana, piel laxa, desviación radial de la muñeca, contractura en flexión de las articulaciones de la rodilla y pie cavo valgo

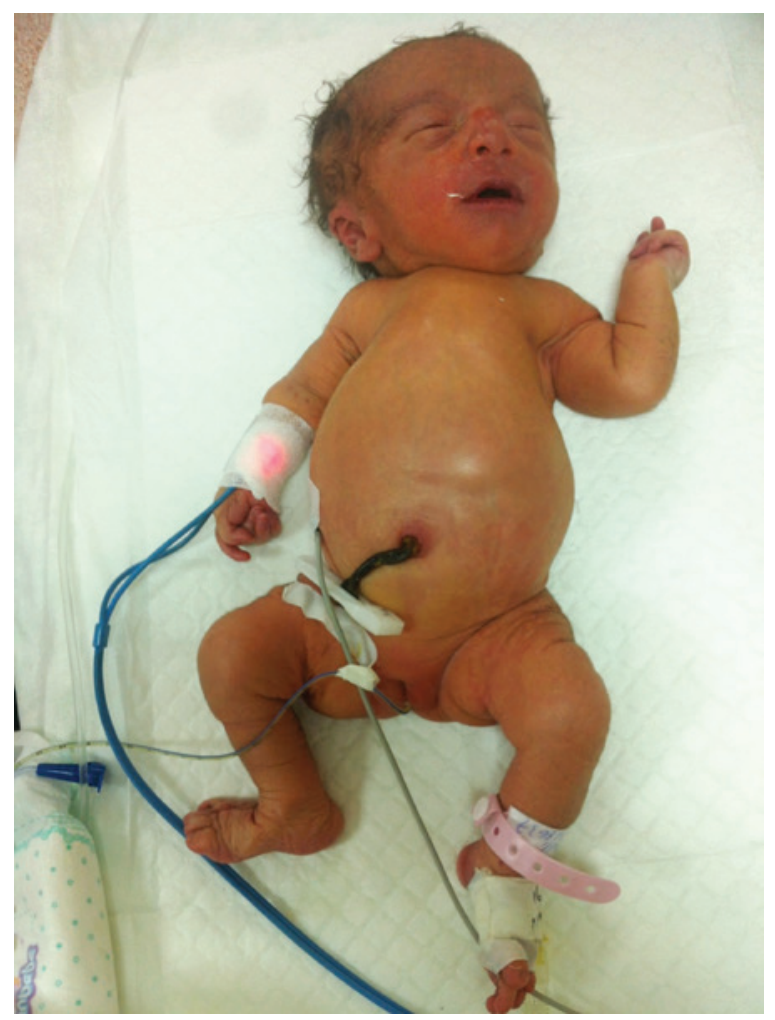


de los órganos afectados incluía el hígado o el riñón y que era potencialmente mortal debido a la tendencia hemorrágica, se evitó la realización de procedimientos invasivos. Teniendo en cuenta todos los signos y resultados de laboratorio, a la paciente se le diagnosticó síndrome de ARC.

La recién nacida no subió de peso a pesar de recibir altas cantidades de líquidos y calorías por nutrición parenteral total, antibióticos por vía intravenosa, ácido ursodesoxicólico y vitaminas liposolubles. Falleció a los 37 días de vida por un cuadro secundario a septicemia.

\section{DISCUSIÓN}

El síndrome de ARC es un trastorno autosómico recesivo infrecuente que afecta principalmente el hígado, los riñones, la piel, el sistema nervioso central y el aparato locomotor. Las causas de este síndrome son las mutaciones en dos genes que interactúan: VPS33B y VIPAS39., ${ }^{2,4}$ Las características típicas de este síndrome son la artrogriposis, la disfunción tubular renal y la colestasis. $^{5}$

La artrogriposis múltiple congénita es el primer signo diagnóstico del síndrome de ARC. ${ }^{6}$ Las anomalías más frecuentes del aparato locomotor en el síndrome de ARC son atrofia muscular, desviación radial de la muñeca, luxación de ambas articulaciones coxofemorales, contractura en flexión de las articulaciones de la rodilla y pie cavo valgo. En este síndrome, también se observan osteopenia y fracturas patológicas debido a la reducida reabsorción de los iones de fosfato a través de los túbulos renales y secundarias a hiperparatiroidismo. ${ }^{2}$ Nuestra paciente estaba hipotónica y tenía desviación radial de la muñeca, contractura en flexión de las articulaciones de la rodilla y pie cavo valgo bilateral. En la ecografía, se observó luxación de ambas articulaciones coxofemorales. Se consideró que la fractura del fémur derecho era resultado de la osteopenia debido a la fosfaturia, los valores elevados de FA y los bajos niveles de fósforo.

Los síntomas más frecuentes del síndrome de ARC son ictericia colestásica y hepatomegalia. En todos los pacientes con síndrome de ARC, se describieron niveles bajos o normales de $\gamma$-GT, niveles levemente elevados de alanina aminotransferasa (ALT) sin obstrucción biliar. La colestasis con niveles bajos de $\gamma$-GT es una de las características típicas del síndrome de ARC. ${ }^{2,4}$ Nuestra paciente tenía hiperbilirrubinemia conjugada y valores normales de transaminasas y $\gamma$-GT, como se ha observado en las publicaciones.
La histología de hígado en los pacientes con síndrome de ARC sugiere escasez de vías biliares, depósito de lipofuscina y hepatitis de células gigantes. ${ }^{7}$ En nuestra paciente, se observó una prolongación de las pruebas de coagulación, por lo que no se pudo realizar una biopsia de hígado debido a la posibilidad de hemorragia.

El tercer componente del síndrome de ARC es la disfunción tubular renal, que se caracteriza por múltiples signos clínicos del síndrome de Fanconi, incluidos glucosuria, fosfaturia, aminoaciduria generalizada y acidosis tubular renal. La disfunción tubular renal podría manifestarse en los primeros días de vida o más tarde, alrededor de los dos o tres meses de vida. ${ }^{2,8,9}$ La mayoría de los pacientes también presentan síntomas de diabetes insípida nefrógena. En una ecografía renal, podría observarse nefrocalcinosis o riñón pequeño displásico. ${ }^{5,9}$ Nuestra paciente tenía tubulopatía renal y diabetes insípida nefrógena. En la ecografía renal, se observó un aumento de la ecogenicidad de ambos riñones. Kim y col., ${ }^{10}$ informaron 12 casos de síndrome de ARC; diez de ellos tenían síndrome de Fanconi y los otros dos, riñones normales. Dado que el síndrome de Fanconi puede aparecer a los dos o tres meses de vida, creemos que, en nuestra paciente, aún no se había presentado.

Ocasionalmente, los pacientes con síndrome de ARC tienen cardiopatías congénitas y anomalías del sistema nervioso central..$^{9,10}$ Nuestra paciente tenía una comunicación interauricular de $2 \mathrm{~mm}$. En la tomografía computada cerebral, se observó dilatación de los ventrículos laterales y del tercer ventrículo y agenesia del cuerpo calloso.

En el síndrome de ARC, pueden verse anomalías trombocíticas congénitas, lo que puede producir una tendencia hemorrágica; por lo tanto, debe estudiarse la morfología de los trombocitos antes de realizar exploraciones invasivas, como la biopsia en un órgano. ${ }^{9}$ El frotis de sangre periférica mostró trombocitos pálidos y de gran tamaño.

Se han informado diversas características dismórficas en este síndrome, como occipucio prominente, orejas de implantación baja y anguladas en la parte posterior, puente nasal plano, hendiduras palpebrales con inclinación hacia arriba, pliegue simiesco, paladar arqueado alto, nariz aguileña, piel laxa y criptorquidia. ${ }^{9}$

En todos los pacientes, se observa un retraso del crecimiento debido a la diarrea y los episodios recurrentes de deshidratación secundaria a la diabetes insípida nefrógena. A menudo, tienen 
diarrea crónica debido a la absorción deficiente de grasa causada por la colestasis. ${ }^{5,9}$ Nuestra paciente tenía retraso del crecimiento secundario a la diabetes insípida nefrógena, aunque no tuvo diarrea.

En el diagnóstico diferencial, se consideró la presencia de atresia biliar. La proporción de ARC y atresia biliar es aproximadamente 1:7, y cabe destacar que, tal vez, no sea tan poco frecuente en ciertos grupos étnicos, pero se descartó dado que las vías biliares eran normales según la ecografía abdominal y los niveles de $\gamma$-GT en suero no estaban elevados. ${ }^{11}$ Los signos clínicos y los resultados de laboratorio del síndrome de ARC y de la colestasis intrahepática familiar progresiva (CIFP) son similares. Es necesario realizar estudios genéticos adicionales para descubrir el gen causante de la CIFP. ${ }^{6}$ Tanto en el síndrome de ARC como en el síndrome de plaquetas grises (SPG), se observan trombocitos pálidos y de gran tamaño, con ausencia de gránulos alfa; sin embargo, el SPG está, por lo general, asociado con trombocitopenia. Por lo tanto, debe evaluarse la morfología de los trombocitos antes de realizar procedimientos invasivos. $^{12}$

Desafortunadamente, no existe una cura para el síndrome de ARC. Todos los pacientes fallecen dentro de unos pocos días o meses a causa de septicemia, deshidratación grave y acidosis. Solo puede instaurarse un tratamiento complementario que incluya la administración de altas cantidades de líquidos y calorías, ya sea por medio de nutrición parenteral total o fórmulas enriquecidas con triglicéridos de cadena media, vitaminas A-D-E-K mensuales y ácido ursodesoxicólico. ${ }^{2}$ Nuestra paciente falleció a los 37 días de vida a causa de septicemia.

Para lograr el diagnóstico e iniciar la terapia en forma temprana, deben investigarse ampliamente los antecedentes familiares y las presentaciones clínicas clásicas y deben analizarse las mutaciones genéticas. Una vez realizado el diagnóstico, debe brindarse asesoramiento genético. El estudio de este paciente tuvo ciertas limitaciones: no fue posible realizar estudios moleculares y no se autorizó la autopsia.

\section{REFERENCIAS}

1. Gissen P, Tee L, Johnson CA, Genin E, et al. Clinical and molecular genetic features of ARC syndrome. Hum Genet 2006;120(3):396-409.

2. Zhou Y, Zhang J. Arthrogryposis-renal dysfunctioncholestasis (ARC) syndrome: from molecular genetics to clinical features. Ital J Pediatr 2014;40:77.

3. Laforgia N, Burattini MG, Giannuzzo S, Storelli S, et al. ARC syndrome. Acta Pædiatr 2005;94(2):254-5.

4. Wang JS, Zhao J, Li LT. ARC syndrome with high GGT cholestasis caused by VPS33B mutations. World J Gastroenterol 2014;20(16):4830-4.

5. Eastham KM, McKiernan PJ, Milford DV, Ramani P, et al. ARC syndrome: an expanding range of phenotypes. Arch Dis Child 2001;85(5):415-20.

6. Tekin N, Durmu -Aydo du S, Dinleyici EC, Bör O, et al. Clinical and pathological aspects of ARC (arthrogryposis, renal dysfunction and cholestasis) syndrome in two siblings. Turk J Pediatr 2005;47(1):67-70.

7. Abdullah MA, Al-Hasnan Z, Okamoto E, Abomelha AM. Arthrogryposis, renal dysfunction and cholestasis syndrome. Saudi Med J 2000;21(3):297-9.

8. Dehghani SM, Bahador A, Nikeghbalian S, Salahi H, et al. Liver transplant in a case of arthrogryposis-renal tubular dysfunction-cholestasis syndrome with severe intractable pruritus. Exp Clin Transplant 2013;11(3):290-2.

9. Nili F, Akbari-Asbaghe P, Oloomi-Yazdi Z, Hadjizadeh $\mathrm{N}$, et al. Wide spectrum of clinical features in a case of arthrogryposis-renal tubular dysfunction-cholestasis syndrome. Arch Iran Med 2008;11(5):569-72.

10. Kim SM, Chang HK, Song JW, Koh H, et al. Agranular platelets as a cardinal feature of ARC syndrome. J Pediatr Hematol Oncol 2010;32(4):253-8.

11. Ganesh R, Uppuluri R, Janakiraman L, Gowrishankar K, et al. Arthrogryposis-Renal dysfunction-Cholestasis (ARC) Syndrome: a case report. Indian J Appl Res 2015;5(3):340-1.

12. Gunay-Aygun M, Zivony-Elboum Y, Gumruk F, Geiger $\mathrm{D}$, et al. Gray platelet syndrome: natural history of a large patient cohort and locus assignment to chromosome $3 \mathrm{p}$. Blood 2010;116(23):4990-5001. 